\title{
Reframing Autism in a Mainstream Classroom via the Constructs of Inclusion and Stigma
}

\author{
Kevin Xuereb and Wenn B. Lawson
}

ACRC, The University of Queensland, C/O PO Box 5033, Warrnambool, Vic. 3280, Australia

\begin{abstract}
An investigation was undertaken to explore the social environment in a mainstream classroom that housed both non-autistic and autistic students. The research focus was to see if engaging students in a particular programme, successfully reduced stigma. The research is founded upon the concept of autism as part of neurodiversity rather than only disorder. It posits affective and social outcomes of inclusive education can be a reality once stigma is exposed and autism, reframed. The literature reviewed yielded valuable insights into how best to support the rationale of this study to prepare typical classmates for entry of autistic children.

Method: Via a single case-study, an engaging and interactive Peer Preparation Programme (PPP) provided opportunities for the pupils and the focus child to interact with each other; enabling them to acquire knowledge about themselves, each other, autism and ways to minimise the negative impact of stigma.
\end{abstract}

Results: Findings indicated a considerable increase in empathetic attitudes, spontaneous interactions, peer awareness, positive peer imitations and peer advocacy.

Conclusions: To reframe autism within mainstream classrooms, although conscious this is a single case-study, the program helped pupils comprehend the sensitive issues of social stigma and encourage empathy in practice.

Keywords: Autism, inclusion, stigma, peer awareness, empathy, mainstream classrooms.

\section{INTRODUCTION}

'Inclusive classrooms' where all students are welcome are usually dominated by a particular neurotype. This promotes acceptance of what is 'normal' and, when students don't fit, stigma ensues [1]. Being part of an inclusive classroom, therefore, does not guarantee autistic pupils' acceptance by their non-autistic peers [2]. The term 'autistic' was chosen to refer to students on the autism spectrum because surveys undertaken to check on preferred language showed most autistic individuals preferred identity first language over person first (see: [3-5]). Congruent with Lawson [3], autism, when appropriately catered for is a 'diff-ability', rather than a disorder, implying autistic individuals learn in a different way to the non-autistic population. Jordan [6] https://onlinelibrary.wiley.com/ doi/pdf/10.1111/j.1467-8578.2008.00364.x suggests autistic individuals progress to becoming 'disordered' when/if their specific needs are not accommodated. Although autism is a pervasive developmental difference, schools that fail to accommodate this difference construct a rudimentary education system that cannot hope to address social oppression and stigma.

In the context of ethical considerations, permissions were sought and granted.

*Address correspondence to this author at the ACRC, The University of Queensland, C/O PO Box 5033, Warrnambool, Vic. 3280, Australia; Birmingham University, UK; Tel: +61 408304371

E-mail: wenbe2@outlook.com

\section{The Issue}

According to Jordan [7], autistic pupils' cognitive and preferred learning styles challenge professional assumptions about teaching and learning more than any other cohort within Special Educational Needs (SEN). Similar concerns expressed by Warnock [8] concerning pupils' experiences of inclusion have highlighted adverse social and affective outcomes. Inclusion advocates argue that if such negative social consequences are produced, then the process of inclusion is bound to lead to poor integration [9].

As Howlin [10] points out, 'inclusion' is about improving the quality of life of all children throughout their educational career and beyond. When an autistic pupil is socially accepted in an inclusive setting, it is likely to be the outcome of quality relationships.

\section{Research Questions this Paper Addresses}

- How can educators decrease stigma related to autism?

- How can schools diminish empathy deficits in our younger generation?

- How can pupils increase their autism awareness?

- How can parents/carers of autistic children contribute with schools to help pupils build adaptive skills in order to accept and include autistic pupils? 
Providing answers to these questions can shine a light on the best way to maintain social relationships and reciprocal friendships between non-autistic and autistic pupils. Therefore, a novel 'Peer Preparation Programme' (PPP), aimed at improving the attitudes and interactions by peers of a child diagnosed with 'Autism, Level 1' in the updated version of DSM-5 [11] was implemented.

\section{LITERATURE REVIEW}

'Inclusive philosophy' is preferred to the word 'inclusion' thus making it clear the way forward should not be limited to only practices but to an overarching perspective that embraces the complex nature of a broader concept of inclusion. Agius Ferrante [12] strongly believes that present perceptions of educators who classify students as normal and disabled are still closely linked to a perspective that values uniformity rather than diversity. Such a perspective is likely to increase stigma by adding another label for SEN. Conversely, an inclusive philosophy adopts:

\section{'...the feeling of belonging, since such a feeling appears to be necessary both for successful learning and for more general well-being' [8, p.15].}

The research documented in this paper addresses issues that frequently lead to loneliness among autistic children and negative attitudes in their non-autistic peers. It demonstrates one positive way to relieve the burden of social stigma in one classroom with potential ripple out affects.

\section{Addressing Empathy Deficits in Classrooms}

A holistic lifelong learning approach is needed to facilitate individuals' future outside school. Academic success cannot by itself help pupils lead rewarding lives; pupils need to be supported to develop empathy skills. These, according to Goleman [13], build on selfawareness and on the ability to read others' feelings and enter another's frame of reference. Hoffman [14] highlighted the central role played by empathy in the development of moral values, (e.g. compassion). He argued it is by empathising with and sharing others' distress that people are moved to help others who are in distress. Therefore, having non-autistic pupils in a mixed ability classroom able to practically empathise is likely to lead to a caring, altruistic and compassionate environment. This ability helps to break down stereotypes and biases, enhances tolerance and boosts acceptance of differences [13].
In autism, the literature tends to emphasise areas of emotional deficit (e.g. [15-17]). A possible explanation for these deficits is the persistence in today's mainstream classrooms of a culture that is inspired by a medical model, that is at odds with an inclusive philosophy. Autistic individuals are concerned about the discrepancy between the celebration of difference and the systematic attempt to normalise conditions based on deficits. Inevitably, this lowers autistic pupils' quality of life as these students end up experiencing inequality and exclusion [18]. This phenomenon could be attributed to accumulated alienation and anomie associated with social groupings that can make autistic individuals feel powerless and marginalised [19]. In this respect, Vygotsky's [20] sociocultural perspective endorsed an inclusive social milieu for autistic children in a regular inclusive classroom. The absence of such a social milieu could exacerbate negative societal expectations and attitudes [21]. Building a culture of empathy can help enhance interpersonal relationships between non-autistic and autistic pupils in mainstream schools [22].

\section{Autism Awareness and Acceptance in Classrooms}

From an insider's perspective, an ideal inclusive philosophy is not about including autistic individuals equally but doing it differently [23]. This necessitates increased tolerance, acceptance and openness to neuro-diversity. However, as Lawson [23] argued, as long as no one attempts to bridge the gap between non-autistic and autistic individuals, diverse strengths and interests remain untapped. International campaigns by United Nations and Autism Speaks (e.g. April as 'Autism Awareness Month' and 'Light it up Blue'), and general surveys (e.g. [24-27]) have been instrumental in raising awareness among general populations. However, Campbell and Barger [28] found that despite a high level of autism awareness among mainstream pupils, autistic peers were still experiencing high levels of isolation, teasing and bullying. Identifying similarities between non-autistic and autistic children in schools is key to acceptance. This may provide a practical remedy to reduce isolation and bullying [24] and turn acceptance into action [29]. Maich and Belcher [30] emphasised the importance of celebrating positive examples of diversity in the characteristics of autistic pupils helping shape positive attitudes of non-autistic peers.

\section{Social Stigma and Autism in Classrooms}

Link and Phelan [31] posited that negative attitudes, comprising similar systems of belief, resulted in 
discrimination against individuals causing shame in associated cohorts. Goffman [32] and Link and Phelan [31], suggest stigma consists of identifying and labelling differences; associating these with negative attributes; out-grouping this particular cohort; and discriminating against the individuals. In mainstream classrooms, negative attitudes towards autistic peers may translate into negative discriminatory behaviours in the form of bullying, fear, disgust and/or annoyance, while shame, embarrassment and belittlement may be experienced by autistic pupils. In autism literature, the concept of stigma has been widely used to analyse the experiences of shame and social exclusion of autistic children's parents [33, 34]. However, there is little associated literature concerning autistic children [35]. Therefore, future research should focus on interventions that help to alleviate the general public's stigmatising views of social behaviours associated with autism.

One plausible reason explaining why so many school initiatives aimed at fighting stigma fall short is that 'stigma' and 'inclusion' are viewed as two separate and opposing constructs [36]. In this respect, some researchers have made a convincing case for the need to eliminate the term 'stigma' which might unconsciously generate negative feelings. Indeed, according to Sayce [36], 'discrimination' or 'exclusion' might be better termed as they carry less negative connotations. However, congruent with Werner et al. [37] and Cobigo and Stuart [38], stigma and inclusion are not opposites, but rather, complementary constructs on the same continuum, and that anti-stigma intervention may be useful to promote social inclusion.

\section{METHODOLOGY}

The development of a novel PPP was disseminated in a mainstream primary classroom in an attempt to educate students about difference and to foster empathy amongst them. It served to provide increased opportunities for the focus child to gain understanding and acceptance, also empowering non-autistic pupils to provide support and develop friendships.

This study draws rich, interconnected information on interactions with the autistic boy - to elicit valuable insights into what is going on in one inclusive classroom.

All participants completed an adapted 'Adjective Checklist' privately [39] to measure cognitive attitudes. This framework was meant to create an avenue platform for the co-construction of qualitative inclusive classroom practices while concurrently enhancing values such as caring, sharing, tolerance, and belonging in a community. The PPP was disseminated throughout the second scholastic term in 4 sessions of approximately an hour each, in 4 consecutive weeks. The focus child's mother delivered this programme to promote a more caring mentality and to raise more affective awareness about her son's diversities. Indeed, her contribution was instrumental in promoting greater tolerance of diversity among all children and fostering a greater sense of acceptance within the school community.

Week one focused on autism awareness and acceptance, delivered mainly through descriptive information in order to highlight similarities. The objective of this session was to give an opportunity to non-autistic pupils to learn about autism and explore similarities and differences between themselves and their autistic peer.

Week two focused on reinforcing the acknowledgement of similarities and differences between individuals in the class. This session's objective was to give all children the chance to explore what it means to be 'unique'. This session featured interactive activities that supported the learnings in the previous session.

Week three was about helping pupils work on and endorse empathy skills which improve self-awareness and increase the ability to read the feelings of others [13]. The week's session helped to reinforce the learnings in previous sessions and encouraged all pupils to acknowledge the issue of relationality between them and the focus child [22]. The objective of this session was to teach pupils how to help others feel better.

Week four of this programme, the heart of this research, sought to expose the meaning of stigma and its repercussions. In line with Corrigan [40], non-autistic pupils were shown examples that allowed for mapping and addressing stigma within their school and community. To this end, a 'PowerPoint' presentation adapted from Melchiori and Mallett's [41] study, explained stigma to the entire class. Clips from the animated movie 'Shrek' [42] were used to illustrate and explore both concealable and non-concealable, stigmarelated concepts.

\section{Data Gathering}

Unstructured observations entailed using personal sensitivity, commitment and deep thought in order to 
gather valuable data and feedback that could be translated into meaningful findings for analysis. Observations were conducted daily for 10 to $15-$ minutes at different times. These were recorded for 24 consecutive school-days, starting after the fourth and last session of the PPP. Unstructured interviews collected in-depth feedback from non-autistic pupils that yielded rich themes throughout the transcripts. Individual diary notes were encouraged by each pupil so that non-autistic pupils could express their deepest thoughts in order to provide useful, rich data. All pupils were encouraged to jot down daily records of thoughts, feelings, actions, responses and snatches of conversations between themselves and their autistic peer. Moreover, a diary was also used by the autistic child, who was asked to keep a daily record of his perceptions and feelings in the classroom.

\section{Data Analysis}

A holistic analytical frame was developed to elicit relevant themes from all data. Qualitative analysis elicited emerging themes from the transcripts of the interviews and highlighted connections, convergencies, divergencies and overlapping themes. A comparative method was used throughout the analysis of data [43, 44]. Issues such as the subject of comparison (reframing autism among non-autistic pupils), the reason for comparison (enhancing quality inclusion and reducing stigma) and results of the comparison (mapping out narratives from raw data that illustrate both subject and reason underpinning comparison) were identified to give a framework to work and increase traceability.

\section{FINDINGS}

Whether or not autistic individuals are vulnerable to neglect when placed in mainstream classrooms is an important question. The first presentation of findings indicates that allocating an autistic child to a mainstream classroom does not guarantee they will be able to interact and learn together with their peers. After the first school semester, the majority of pupils still described their autistic peer by choosing adjectives from their checklist that have a negative connotation. This indicates that the focus child might have been vulnerable to neglect [8].

Moreover, his negative social expectations and attitudes might be exacerbated if not addressed [21]. From a total of 11 non-autistic participants, 10 perceived their autistic peer as 'lonely', 9 as 'sad and shy', 8 as 'weird' and 6 as 'thoughtless and passive'.
Interestingly, consistent with Milton's [45] argument, although all pupils perceived their autistic peer as a 'good boy', no one seemed to bother to get to know him better. This data indicates poor social and affective outcomes [46], suggesting 'inclusion' might lead to 'poor integration' [9].

\section{Which Construct: 'Inclusion’ or 'Stigma'?}

Sayce [36] argues that the terms 'stigma' and 'inclusion' are to be viewed as two separate and opposing constructs. Undeniably, the elimination of the term 'stigma' was reflected in the autism literature, as little can be found on the dramatic effects it has on autistic pupils [35]. In considering this case study, however, which revolves around both constructs, Sayce's [36] ideology is challenged. Instead, via inductive reasoning, this research endorses the conclusions of Werner et al. [37] and Cobigo and Stuart [38], who believed that these terms complement each other. The dissemination of knowledge on the negative effects of stigma, its meaning and its process can lead to an ever-increasing sense of inclusion and acceptance of autism. In line with Corrigan [40], the PPP attempts to remove the stigma from this particular classroom in order to let true inclusion occur. The following emerging themes point towards the possibility that autism can be reframed.

\section{Theme 1: Empathy}

Milton [45] insists that the failure of autistic people to empathise effectively with non-autistic people is amplified by the routine failure of this population to understand what autistic people are actually feeling. It is non-autistic empathy that has been studied and tested throughout this case-study, to identify and improve empathy levels of non-autistic pupils towards their autistic peer. Several findings are of particular interest regarding improved empathetic skills that empower non-autistic pupils to take steps to be supportive [14]. This indicates that pupils at this age are willing to use their honed empathy skills, which are conducive to the creation of a caring and compassionate environment [13]. The 'us and them' dichotomy that might further lead to stigma is addressed and minimised. Revealingly, these findings challenge Bauminger et al.'s [47] assertion that autistic pupils are isolated in unstructured social environments. If pupils can develop positive attitudes, they can be seen as strategists, able to choose courses of action and decide for themselves whether to empathise with the focus child or shun them [48]. 


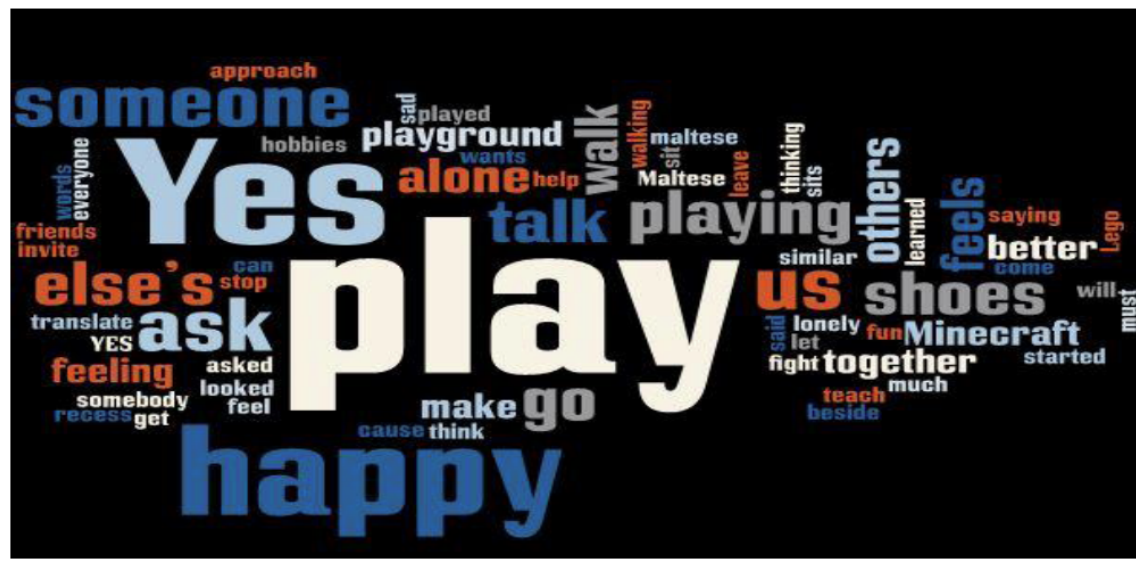

Graphical Representation: Word frequency gives greater prominence to words that appear more frequently. The larger the word in the visual representation, the more often it was mentioned.

Indeed, findings indicate that most pupils were able to see themselves as responsible for taking action and putting themselves in their autistic peer's shoes. The most highlighted concern was the need to include their autistic peer in their play, during a time they perceived him as most 'lonely'. Play is of vital importance to primary-aged children's development as it is an essential means of exploring, expanding and representing cognitive and emotional experiences [49]. It is therefore highly satisfying that the word 'play' featured prominently along with the word 'happy' which describes how they felt when their autistic peer was being included. Again, this finding runs counter to Bauminger et al. [47], as it demonstrates a model of inclusive practice that mitigates social distance and stigma during outdoor play. Moreover, almost all children reported positive feelings of well-being when they realised that their autistic peer was also feeling happy as the extract below taken from the interviews show.

\begin{abstract}
'Yes today in the playground he was by himself, and I went to talk to him. Then everyone came, and we were all playing, and someone hit his eye with the ball, and he got hurt. And I told him: 'Go wet your eye'. Then we all played together again, and everyone was happy'
\end{abstract}

Crucially, most diary notes recorded instances of empathy that are consistent with the findings elicited from interviews. Most pupils recorded their practice of empathy through play during recess time and helped during group-work. Again, this resonates with strong evidence that the empathy practised can pave the way to quality inclusive practice by gradually mitigating social exclusion and stigma.
Another revealing finding that emerged from the data is in consonance with similar findings in the study conducted by Milton [45], who concluded that autistic individuals might also possess 'empathy'. Reciprocated empathetic attitudes between non-autistic and autistic pupils generate energy and enthusiasm in supporting pupils to challenge negative expectations of autism and to downplay social distance and stigma.

\section{Sub-Theme 1: Peer Awareness}

It is likely that the level of autism awareness affects non-autistic pupils' negative or positive perception of their autistic peer. Data drawn from interviews was used to test the hypothesis on improved openness to and tolerance of this autistic individual. The interview questions revolved around non-autistic pupils' knowledge of autism and their individual similarities and differences. The interview questions also inquired how pupils dealt with challenges that stemmed from their autistic peer's character. Knowing what makes the individual in focus tick is bound to lead to a deeper understanding.

As evidenced, most pupils were particularly interested in identifying common grounds of similarity rather than differences. This might indicate that when pupils think about others, they prefer to seek similarities and positive strengths in order to interact in a friendlier way. Indeed, congruent with Maich and Belcher [30], the current study found that when the emphasis is on seeking similarities and positive examples of diversity, attitudes can be improved. This may be one practical remedy to reduce isolation [24], and greater acceptance might lead to concrete steps to turn favourable attitudes into action [29]. The ultimate aim here is to eliminate stigma from this group to let true inclusion occur [40]. 
Before incorporating peer awareness within a framework, it was revealing to analyse whether acknowledging differences or recognising individual similarities is the more effective way of addressing stigma and social distance. The outcomes were then compared to data drawn from the unstructured observations. It was observed non-autistic pupils were more concerned about their autistic peer's differences. This might indicate a common pitfall often undermining the practice of inclusion in inclusive institutions, where inclusion is advocated, but, with a 'normal' and 'less normal' perspective. This faulty practice is that the 'normal' needs to help the 'less normal' to become 'more normal' [12]. However, though mindful of this pitfall, in this case-study non-autistic helped their autistic friend achieve success. This indicates that the positive outcome stemmed from their gained knowledge and acceptance of differences presented by their peer. Perhaps, some pupils might have learnt the know-how to act at the right time to avoid any tantrums from escalating. When peer awareness was included in a framework that strives to reframe autism, non-autistic pupils were more likely to accept the close proximity of the autistic child. This positive outcome is in line with Allport's [50] contact theory and Heider's [51] cognitive consistency theory.

\section{Theme 2: Spontaneous Interactions}

'Using strengths and skills related to an autism spectrum individual's interest can become the engine that drives mutual understanding'. [3 pp.167].

Although it is outside the scope of this study to be quantitative, it is worth highlighting countless spontaneous interactions when common interests were present. In understanding an insider's perspective, one fundamental aim of a social conversation for most autistic individuals is to appreciate the know-how and to align one's interests with those of the other person [3]. Therefore, as mainstream educators, we must strive to create, facilitate and support the practice of social interactions. Interpreting observed interactions highlight the theme of spontaneous interactions that is of central significance as it helps to address the research questions.

Overall, this data indicates common ground between autistic and non-autistic pupils may be conducive to creating the right conditions to reframing autism. Congruent with Koegel et al. [52], the pupils' common interests and hobbies in this study promoted positive and direct interactions. The implication is that when non-autistic pupils engage spontaneously with their autistic peer, they are contributing to reframe autism. Consequently, this may be a natural and practical remedy for frequent social conversations that may increase opportunities for the autistic child to practise how to align their interests with those of their non-autistic counterparts [3].

To this end, finding commonalities can help avoid the struggles, faced by non-autistic pupils when paired with an autistic peer, reported in many of the studied interventions based on peer-modelling [53]. Findings of this research on spontaneous interactions between non-autistic pupils and their autistic peer are consistent with those by DiSalvo and Oswald's [54] peer-mediated study which suggested the subject of common interests should feature in future research. They advocate the need to refine interventions that can alter non-autistic pupils' expectations, so interactions with their autistic peers can be as intrinsically motivated as possible. Moreover, natural conversations may have longer-term effects and may, over time, correct misattribution and improve affective responding among non-autistic pupils [55].

Congruent with Thomas [56], Burr [48] and Creswell [57], the general criterion for interpretative research is to keep referring to the analysis to generate theoretical developments and a spirit of inquiry in order to shine a light on previous research findings. When the autistic child answered the question on what he liked to talk about most with his peers by responding: 'Things I like', the long pauses and the way he changed his response when asked to specify if he talked about common interests, indicate that he felt uneasy if he was trying to share commonalities with the other pupils or whether he was self-centred in talking about the things he liked. When an autistic character is judged by non-autistic pupils as too egocentric, it is precisely at this moment that educators need to intervene in order to ensure fair practice and to reinforce non-autistic pupils' ability to understand autism. It is understandable that finding common ground may not always be easy, and this could pose challenges for further research on how best to find common ground. However, when non-autistic pupils start distancing themselves from their autistic peer, intervention to avoid isolation and further stigma, becomes essential.

\section{Sub-Theme 2a: Peer Imitations - Attitudes/Behaviour}

The above research findings indicate non-autistic pupils liked the idea of having their intervention 
disseminated by the mother of their autistic peer. As hypothesised, this vicarious experience seems to have heightened non-autistic pupils' empathy and increased understanding of a mother who wants the best for her child; as they believed their own mother would feel and do. Indeed, all of the participants answered in their interviews that they liked this idea. Moreover, all children reported that they felt a deep sense of satisfaction seeing his mother feeling happy for her son. Furthermore, this data suggests that most nonautistic pupils would welcome third parties for such interventions that are instrumental in reframing autism in mainstream settings. The implication is that parents/carers of autistic children can join forces with mainstream schools to enhance non-autistic pupils' adaptive skills that can promote the acceptance and inclusion of autism.

The aforementioned themes can be compressed into one intervention. Having primary carers disseminating such a complex intervention can be instrumental in improving non-autistic pupils' attitudes

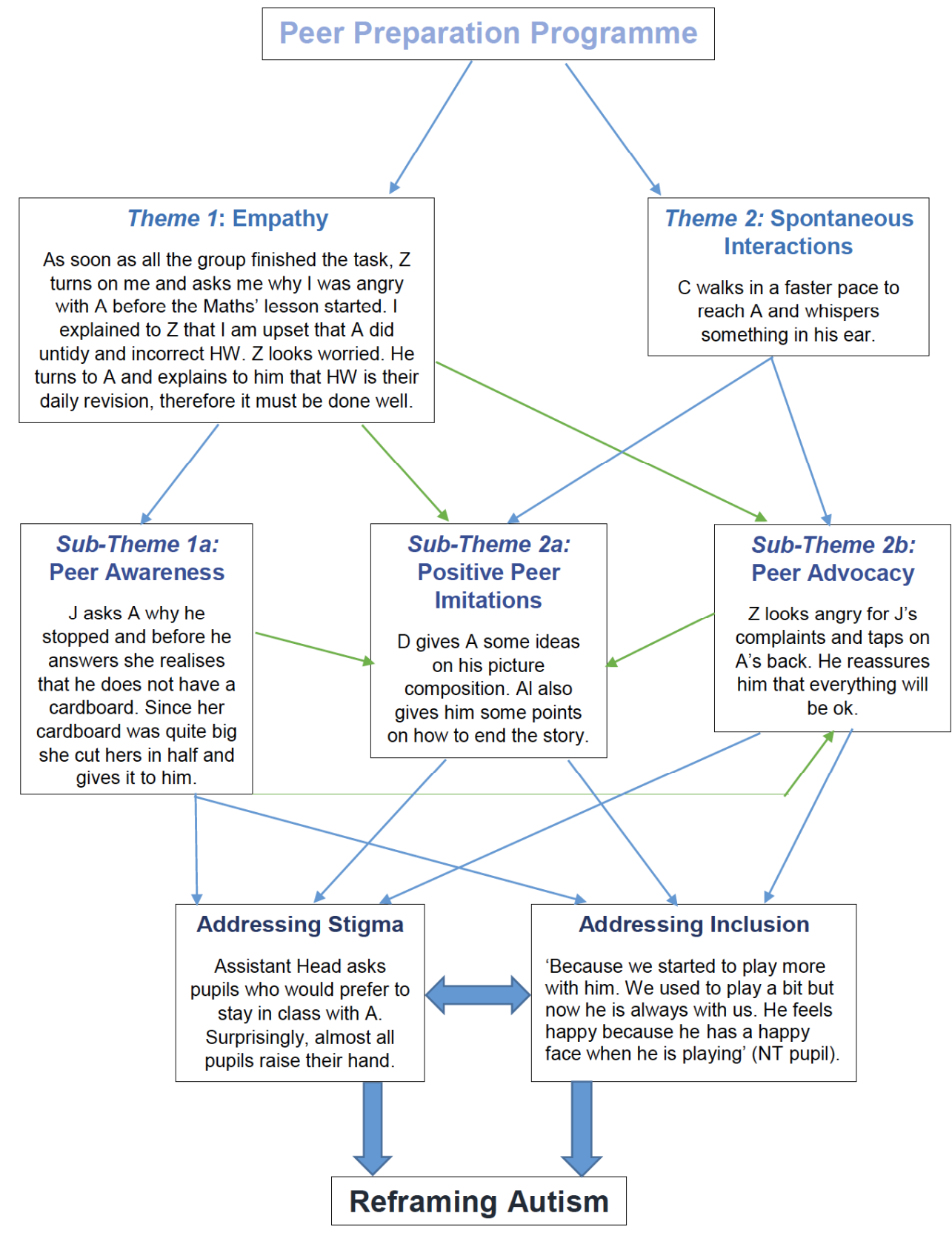

Theme Map - Intertwining themes that attempt to reframe autism in a mainstream classroom. Light blue arrows denote one theme accounting for another theme. Light green arrows denote one theme that seems to be connecting with another theme. NT pupils are addressed by their initials while the focus child is addressed with an A. 
towards their autistic peer, due to possibly heightened emotional intelligence. Therefore, being heedful of each non-autistic pupils attitude that was imitated by another non-autistic pupils attitude is crucial to this outlook. It seems likely, however, that negative attitudes that might occur during the ebb and flow of real interactions might still be followed by another negative response. It is necessary to acknowledge, as discussed further in the next sub-theme, the influence that prevailing peer-models might have within a cohort, which can shape an individual's view. It is, therefore, pivotal to address negative attitudes that may generate other negative responses.

\section{Sub-Theme 2b: Peer Advocacy}

The theme of peer advocacy was demonstrated when non-autistic pupils addressed autism by gathering together solidarity and a network of support. These pupils bear witness to an ability to offer several opportunities for defensive coping, problem-solving and informal learning. The evidence indicates that everyday social experiences [50], along with dissemination of descriptive and explanatory information [55] may provide unprompted and supportive, empathetic peer advocacy, that might further contribute to reframing autism. Unprompted peer advocacy that emerged in the present study points towards an effective intervention, which mitigates empathy deficits and enhances individual peer awareness. It also implies that most pupils can gain a better understanding of their autistic peer and become more supportive.

\section{Reframing Autism in a Mainstream Classroom via the Constructs of 'Inclusion' and 'Stigma'}

To sum up this analysis, the discussion of the aforementioned themes and sub-themes was aimed at addressing the presence of stigma and producing the best interventions to defeat this phenomenon [40] from this particular classroom. In this way, a higher quality of inclusive practice that concerns autism could be achieved in the sphere of social and affective outcomes [46]. Drawing upon this study's results and keeping up to speed with the latest critical autism studies that highlight autism as an integral part of an individual $[1,3,4]$, has outlined reasons to prefer peer-group interventions to peer-mediated interventions. It is often argued that the latter might focus unintentionally on having autistic pupils trying to learn how to act as nonautistic pupils without learning about their own ways of functioning [1].

\section{DISCUSSION}

This research aimed to improve autistic and nonautistic pupils' ways of functioning that encouraged unprompted peer-support. It showed possible outcomes of a concerted effort to reframe autism via the constructs of 'inclusion' and 'stigma'. The construct of 'inclusion' is targeted by the acquisition of positive knowledge and attitudes that acknowledge autistic differences. The construct of 'stigma' is presented by the 'hard-sell' provision of less positive knowledge that focuses on its dramatic, potentially traumatising effects with a view to making pupils examine and judge their own at times prejudiced and stereotyped attitudes. The above theme map correlates all themes with a view to reframing autism among young pupils. As hypothesised, the foundation of this intervention stemmed from a significant increase in empathetic attitudes and spontaneous interactions. Indeed, findings in studies on spontaneous peer-awareness and peer-advocacy resonate with similar findings in research on inclusive practice that emphasises social benefits gained by disseminating such knowledge. These results strengthen the argument that non-autistic pupils can serve as good models without extensive training and prompting [58]

Promoting quality inclusive practice leads to a decline in negative attitudes that undermine the quality of school life of an autistic individual. Peer advocacy increases emotional intelligence and helps pupils adopt less stigmatising views on atypical behaviours associated with autism. This research corroborates Schachter et al.'s [59] belief that educators should evaluate strategies that target stigma on attitudes and behaviour through field observations. Furthermore, with respect to the construct of 'stigma' though deemed negatively by some researchers (e.g. [37]), most participants in this study viewed their lesson concerning 'stigma' as highly interesting.

The analysis is in line with Thornicroft et al. [60], who advocated education on negative effects of stigma and direct social contact as active ingredients to minimise stigma coming from a community, in this case, from a mainstream classroom.

\section{LIMITATIONS AND RECOMMENDATIONS}

In relation to this cohort, this sample is relatively small. Consequently, the classroom's ethnography might be far less complex than any classroom of over twenty pupils. Moreover, it is possible that the autistic 
child himself, though previously deemed 'weird' and 'lonely', possibly distorted and skewed this study's results due to sharing interests and strengths with the other children, such as being verbal and considered to be functioning on the higher end of the autism spectrum. It is also acknowledged that if the intervention had been disseminated at the beginning of the scholastic year, a longer time-frame for the evaluation would have been possible. Moreover, data gathering was implemented right after the dissemination of the intervention, and this could have generated bias as some participants would have known the purpose of the study.

However, there are several fruitful lines of thought within this study that can be the subject of further research in this area. Although this study cannot be generalised, it could be replicated with other classroom cohorts in which other autistic pupils with varying severities along the continuum are present. Moreover, conducting studies with persons from different age groups could provide a better understanding of the outcomes of similar interventions, thus giving a clearer picture of how pupils' views of autism change over time. Furthermore, just as autism is complex, so is empathy among members of a hypothetical classroom. Despite the challenges of diversity, this study can hopefully serve as a valuable tool for educators to gain an insight into young pupils' emotional responsiveness.

\section{CONCLUSION}

While most debates concerning inclusion and autism focus on the importance of awareness and tolerance, it is equally important to highlight the series of steps which can allow this to happen. These findings shine a light on a very complex field of inquiry that is always changing and expanding as it strives to meet society's expectations and achieve economic wellbeing. This case study represents a snapshot of an ideal inclusive classroom, where autism is an integral part of an individual [3] free from discrimination and supported by peers.

For autistic pupils to acquire a sense of belonging within a classroom, therefore, the constructs of inclusion and stigma are equally conducive to improving peer awareness and reframing perceptions of autism. The most satisfying part of this study saw this typical mainstream classroom genuinely striving to improve their empathetic skills and peer awareness, thus creating the right conditions that helped the autistic child feel more understood and supported, and evince a sense of belonging that gave him joy and happiness.

\section{REFERENCES}

[1] Bertilsdotter Rosqvist $\mathrm{H}$. Bertilsdotter Rosqvist $\mathrm{H}$. Knowing What to Do: Exploring Meanings of Development and Peer Support Aimed at People with Autism. International Journal of Inclusive Education 2018; 1(1): 1-14.

[2] Humphrey N, Hebron J. Bullying of Children and Adolescents with Autism Spectrum Conditions: A State of a Field Review. International Journal of Inclusive Education 2015; 19(8): 845862.

https://doi.org/10.1080/13603116.2014.981602

[3] Lawson W. The Passionate Mind. London: Jessica Kingsley Publishers 2011.

[4] Loomes G. It's Only Words: A Critical 'Insider' Perspective on the Power of Diagnosis in the construction of Autistic Social Identity. Good Autism Practice (GAP) 2017; 18(1): 20-24.

[5] Autism CRC. About Us [Internet]. Autism CRC. 2017 [cited 26 November 2017]. Available from: https://www.autismcrc. com.au/about-us

[6] Jordan, $\mathrm{R}$ https://onlinelibrary.wiley.com/doi/pdf/10.1111/ j.1467-8578.2008.00364.x

[7] Jordan R. Autistic Spectrum Disorders. In: Lewis A, Norwich B, ed. by. Special Teaching for Special Children? 1st ed. Buckingham: Open University Press 2005; pp. 110-122.

[8] Warnock M. Special Educational Needs: A New Outlook. London: Philosophy of Education Society of Great Britain 2005.

[9] Frederickson N, Simmonds E, Evans L, Soulsby C. Assessing the Social and Affective Outcomes of Inclusion British Journal of Special Education 2007; 34(2): 105-115. https://doi.org/10.1111/j.1467-8578.2007.00463.x

[10] Howlin P. Autism: Preparing for Adulthood. London: Routledge 1997.

[11] American Psychiatric Association. Diagnostic and Statistical Manual of Mental Disorder. 5th ed. Arlington: American Psychiatric Publishing 2013. https://doi.org/10.1176/appi.books.9780890425596

[12] Agius Ferrante C. A Case Study of Inclusion and Diversity: A Whole School Approach Using the Social Model of Disability [Doctoral Thesis]. Northumbria University 2012.

[13] Goleman D. Emotional Intelligence. London: Bloomsburry 1996.

[14] Hoffman M. Empathy, Social Cognition and Moral Action. In: Kurtines W, Gerwitz J, ed. by. Moral Behaviour and Development: Advances in Theory, Research and Applications. New York: John Wiley and Sons 1984.

[15] Frith U. Autism: Explaining the Enigma. Oxford: Blackwell 2003.

[16] Ozonoff S, Pennington B, Rogers S. Are There Specific Emotion Perception Deficits in Young Autistic Children? Journal of Child Psychology and Psychiatry 1990; 31(1): 587601.

https://doi.org/10.1111/j.1469-7610.1990.tb01574.x

[17] Prior M, Dahlstrom B, Squires T. Autistic Children's Knowledge of Thinking and Feeling States in Other People. Journal of Child Psychology and Psychiatry 1990; 31(4): 587-601. https://doi.org/10.1111/j.1469-7610.1990.tb00799.x

[18] Beauchamp-Pryor K. Impairment, cure and identity: 'where do I fit in?' Disability \& Society $2011 ; 26(1): 5-17$ https://doi.org/10.1080/09687599.2011.529662

[19] Milton D. Disposable dispositions: reflections upon the work of Iris Marion Young in relation to the social oppression of autistic people. Disability \& Society 2016; 31(10): 1403-1407. https://doi.org/10.1080/09687599.2016.1263468 
[20] Vygotsky L. Mind in Society: The Development of Higher Psychological Process. Cambridge: Harvard University Press 1978.

[21] Morcom V, MacCallum J. Getting personal about values: scaffolding student participation towards an inclusive classroom community. International Journal of Inclusive Education 2012; 16(12): 1323-1334.

https://doi.org/10.1080/13603116.2011.572189

[22] Riess H. The Power of Empathy [Internet]. 2013 [cited 18 November 2017]. Available from: https://www.youtube.com/ watch? $v=$ baHrcC8B4WM\&t=480s

[23] Lawson W. Autism - The future I'd like to see - Dr Wenn Lawson [Internet]. National Autism Project. 2017 [cited 26 November 2017]. Available from: http://nationalautismproject. org.uk/the-future-id-like-to-see-wenn-b-lawson

[24] Dillenburger K, Jordan J, McKerr L, Devine P, Keenan M. Awareness and knowledge of autism and autism interventions: A general population survey. Research in Autism Spectrum Disorders 2013; 7(12): 1558-1567. https://doi.org/10.1016/j.rasd.2013.09.004

[25] Durand-Zaleski I, Scott J, Rouillon F, Leboyer M. A first national survey of knowledge, attitudes and behaviours towards schizophrenia, bipolar disorders and autism in France. BMC Psychiatry 2012; 12(1). https://doi.org/10.1186/1471-244X-12-128

[26] Stewart S. I Exist: The message from adults with autism in Northern Ireland [Internet]. Ark.ac.uk. 2008 [cited 18 November 2017]. Available from: https://www.ark.ac.uk/nilt/ results/IExistNI.pdf

[27] National Autistic Society. Autism and Independence [Internet]. 2017 [cited 26 November 2017]. Available from: http://file:///C:/Users/User/Downloads/Autism\%20and\%20ind ependence.pdf

[28] Campbell J, Barger B. Peers' knowledge about attitudes towards students with autism spectrum disorders. In: Patel V, Preedy V, Martin C, ed. by. Comprehensive Guide to Autism. New York: Springer 2014; pp. 247-261. https://doi.org/10.1007/978-1-4614-4788-7 7

[29] Gardiner E, larocci G. Students with Autism Spectrum Disorder in the University Context: Peer Acceptance Predicts Intention to Volunteer. Journal of Autism and Developmental Disorders 2013; 44(5): 1008-1017. https://doi.org/10.1007/s10803-013-1950-4

[30] Maich K, Belcher E. Using Picture Books to Create Peer Awareness About Autism Spectrum Disorders in the Inclusive Classroom. Intervention in School and Clinic 2011; 47(4): 206-213.

https://doi.org/10.1177/1053451211424600

[31] Link B, Phelan J. Conceptualizing Stigma. Annual Review of Sociology 2001; 27(1): 363-385.

https://doi.org/10.1146/annurev.soc.27.1.363

[32] Goffman E. Stigma: Notes on the Management of Spoiled Identity. Eaglewood Cliffs: Prentice Hall Inc. 1963.

[33] Gray D. Perceptions of stigma: the parents of autistic children. Sociology of Health and Illness 1993; 15(1): 102-120. https://doi.org/10.1111/1467-9566.ep11343802

[34] Farrugia D. Exploring stigma: medical knowledge and the stigmatisation of parents of children diagnosed with autism spectrum disorder. Sociology of Health \& Illness 2009; 31(7): 1011-1027.

https://doi.org/10.1111/j.1467-9566.2009.01174.x

[35] Campbell J. Changing Children's Attitudes Toward Autism: A Process of Persuasive Communication. Journal of Developmental and Physical Disabilities 2006; 18(3): 251272.

https://doi.org/10.1007/s10882-006-9015-7

[36] Sayce L. Stigma, discrimination and social exclusion: What's in a word? Journal of Mental Health 1998; 7(4): 331-343. https://doi.org/10.1080/09638239817932
[37] Werner S, Corrigan P, Ditchman N, Sokol K. Stigma and intellectual disability: A review of related measures and future directions. Research in Developmental Disabilities 2012; 33(2): 748-765.

https://doi.org/10.1016/j.ridd.2011.10.009

[38] Cobigo V, Stuart H. Social inclusion and mental health. Current Opinion in Psychiatry 2010; 23(5): 453-457. https://doi.org/10.1097/YCO.0b013e32833bb305

[39] Campbell J, Ferguson J, Herzinger C, Jackson J, Marino C Combined descriptive and explanatory information improves peers' perceptions of autism. Research in Developmental Disabilities 2004; 25(4): 321-339. https://doi.org/10.1016/j.ridd.2004.01.005

[40] Corrigan P. Empowerment and serious mental illness: Treatment partnerships and community opportunities. Psychiatric Quarterly 2002; 73(3): 217-228. https://doi.org/10.1023/A:1016040805432

[41] Melchiori K, Mallett R. Using Shrek to Teach About Stigma. Teaching of Psychology 2015; 42(3): 260-265. https://doi.org/10.1177/0098628315589502

[42] Adamson A, Jenson V. Shrek. Burbank, CA: DreamWorks Pictures 2001.

[43] Thomas G. How to do your research project. 2nd ed. London: Sage 2013.

[44] Boeije H. A purposeful approach to the constant comparative method in the analysis of qualitative interviews. Quality and Quantity 2002; 36(4): 391-409. https://doi.org/10.1023/A:1020909529486

[45] Milton D. On the ontological status of autism: the 'double empathy problem'. Disability \& Society 2012; 27(6): 883-887. https://doi.org/10.1080/09687599.2012.710008

[46] Department for Education and Skills. Removing Barriers to Achievement: The Government's Strategy for SEN. London: DfES 2004.

[47] Bauminger N, Shulman C, Agam G. Peer interaction and loneliness in high-functioning children with autism. Journal of Autism and Development Disorders 2003; 33(5): 489-507. https://doi.org/10.1023/A:1025827427901

[48] Burr V. Social Constructionism. 3rd ed. London: Routledge 2015.

https://doi.org/10.4324/9781315715421

[49] Greenhalgh P. Emotional growth and learning. London: Routledge 1994.

[50] Allport G. The nature of prejudice. New York: Basic Books 2008.

[51] Heider F. The Psychology of Interpersonal Relations. New York: John Wiley 1958.

https://doi.org/10.1037/10628-000

[52] Koegel R, Fredeen R, Kim S, Danial J, Rubinstein D, Koegel L. Using Perseverative Interests to Improve Interactions Between Adolescents with Autism and Their Typical Peers in School Settings. Journal of Positive Behavior Interventions 2012; 14(3): 133-14. https://doi.org/10.1177/1098300712437043

[53] Haney M. After School Care for Children on the Autism Spectrum. Journal of Child and Family Studies 2011; 21(3): 466-473. https://doi.org/10.1007/s10826-011-9500-1

[54] DiSalvo C, Oswald D. Peer-Mediated Interventions to Increase the Social Interaction of Children With Autism. Focus on Autism and Other Developmental Disabilities 2002; 17(4): 198-207. https://doi.org/10.1177/10883576020170040201

[55] Campbell J, Barger B. Middle School Students' Knowledge of Autism. Journal of Autism and Developmental Disorders 2010; 41(6): 732-740.

https://doi.org/10.1007/s10803-010-1092-x 
[56] Thomas G. How to do your case study. 2nd ed. London: Sage 2016.

[57] Cresswell J. Qualitative inquiry and research design. Choosing among five traditions. London: Sage 1998.

[58] Garfinkle A, Schwartz I. Peer Imitation. Topics in Early Childhood Special Education 2002; 22(1): 26-38. https://doi.org/10.1177/027112140202200103
[59] Schachter H, Girardi A, Ly M, Lacroix D, Lumb A, van Berkom J, et al. Effects of school-based interventions on mental health stigmatization: a systematic review. Child and Adolescent Psychiatry and Mental Health 2008; 2(1). https://doi.org/10.1186/1753-2000-2-18

[60] Thornicroft G, Brohan E, Kassam A, Lewis-Holmes E. Reducing stigma and discrimination: candidate interventions. International Journal of Mental Health Systems 2008; 2(1): 3. https://doi.org/10.1186/1752-4458-2-3

DOI: https://doi.org/10.6000/2292-2598.2019.07.03.1

(C) 2019 Xuereb and Lawson; Licensee Lifescience Global.

This is an open access article licensed under the terms of the Creative Commons Attribution Non-Commercial License (http://creativecommons.org/licenses/by-nc/3.0/) which permits unrestricted, non-commercial use, distribution and reproduction in any medium, provided the work is properly cited. 